\title{
Taninos: principal componente do extrato Piptadenia stipulacea (Benth) Ducke inibe o crescimento de cepas clínicas de Staphylococcus aureus de origem bovina
}

\author{
Vanessa de Melo Cavalcanti-Dantas ${ }^{1}$ \\ Kézya Lopes de Medeiros ${ }^{1}$ \\ Tatiane Kelly Barbosa de Azevêdo ${ }^{2}$ \\ Gregório Mateus Santana ${ }^{2}$ \\ Andréia Vieira Pereira ${ }^{3 *}$ \\ Marcelo Biondaro Góis ${ }^{4}$ \\ Maria do Socorro Vieira Pereira ${ }^{1}$ \\ Jozinete Vieira Pereira ${ }^{5}$ \\ ${ }^{1}$ Universidade Federal da Paraíba, João Pessoa - PB, Brasil \\ ${ }^{2}$ Universidade Federal de Campina Grande, Patos - PB, Brasil \\ ${ }^{3}$ Universidade Estadual de Londrina \\ Rodovia Celso Garcia Cid, Campus Universitário, CEP 86057-970, Londrina - PR, Brasil \\ ${ }^{4}$ Universidade Estatual de Maringá, Maringá - PR, Brasil \\ ${ }^{5}$ Universidade Estadual da Paraíba, Campina Grande - PB, Brasil \\ *Autor para correspondência \\ andreiavet@hotmail.com
}

Submetido em 25/05/2015

Aceito para publicação em 10/12/2015

\section{Resumo}

Este estudo avalia a atividade antimicrobiana dos taninos presentes na casca do caule da Piptadenia stipulacea (Benth) sobre cepas de Staphylococcus aureus de origem bovina. A atividade antimicrobiana in vitro do tanino foi avaliada pela determinação da concentração mínima inibitória (CIM). Para determinar a CIM, os taninos foram dissolvidos de forma seriada em água destilada em concentrações variando entre $500 \mathrm{mg} / \mathrm{mL}$ e $0,976 \mathrm{mg} / \mathrm{mL}$. Os ensaios foram realizados em triplicata. Os taninos inibiram o crescimento de S. aureus, apresentando valor de CIM de $31,25 \mathrm{mg} / \mathrm{mL}$. Os resultados deste estudo são promissores, pois mostram a importância de avaliar novos compostos de origem natural no combate às infecções causadas por S. aureus. Novos estudos são necessários para confirmar a atividade in vivo e avaliar o mecanismo de ação do tanino isolado da casca do caule da Piptadenia stipulacea.

Palavras-chave: Bovino; Microrganismos; Produto natural

\section{Abstract}

Tannins: main component of the extract Piptadenia stipulacea (Benth) Ducke inhibits growth of Staphylococcus aureus clinical strains of bovine origin. This study evaluates the antimicrobial activity of tannins observed on the stem bark of Piptadenia stipulacea (Benth) on Staphylococcus aureus strains of bovine 
origin. In vitro antimicrobial activity of the tannin was evaluated by determining the minimum inhibitory concentration (MIC). To determine the MIC, tannins were serially dissolved in distilled water at concentrations ranging between $500 \mathrm{mg} / \mathrm{mL}$ and $0.976 \mathrm{mg} / \mathrm{mL}$. Assays were performed in triplicate. Tannins inhibited the growth of $S$. aureus, showing $31.25 \mathrm{mg} / \mathrm{mL}$ as the MIC value. The results of this study are promising, as they show the importance of evaluating new compounds of natural origin that fight against infections caused by $S$. aureus. Further studies are needed to confirm in vivo activity and evaluate the action mechanism of tannin isolated from the stem bark of Piptadenia stipulacea.

Key words: Bovine; Microorganisms; Natural product

\section{Introdução}

O Staphylococcus aureus está entre as bactérias patogênicas mais isoladas em infecções adquiridas em humanos por causar muitas enfermidades. Dentre elas, destaca-se a pneumonia e a meningite (PEREIRA et al., 2004; TRABULSI; ALTERTHUM, 2009). Em animais de produção são responsáveis por processos infecciosos da glândula mamária como a mastite, prejudicando diretamente na qualidade do leite e acarretando perdas à indústria leiteira por interferir na elaboração de derivados (MELLO et al., 2012). Ainda, esse microrganismo representa potencial risco à saúde pública, uma vez que apresenta alto grau de toxigenicidade, ocasionando riscos à saúde pública (TREVISAN et al., 2009; VIÇOSA et al., 2010; MELLO et al., 2012; KOZERSKI et al., 2014).

São muitos os fatores de virulência que contribuem para a patogenicidade de $S$. aureus e que o permitem ser tão bem sucedido, como: a capacidade de disseminação; a formação de cápsula; síntese de proteína A, de enzimas e toxinas constituintes da parede celular; capacidade de adaptação e resistência a antibióticos (SANTOS et al., 2007; KLEIN; GOULART, 2008; KOZERSKI et al., 2014).

A resistência às substâncias antimicrobianas comuns pode, em parte, ser atribuída ao uso abusivo de antibióticos, o que dificulta o tratamento de infecções bacterianas.

Santos et al. (2007) demonstraram que $70 \%$ a $100 \%$ das infecções causadas por S. aureus envolvem amostras resistentes e multirresistentes. Bactérias antes sensíveis aos antibióticos usados na rotina clínica estão se tornando cada vez mais resistentes, fato que tem motivado o interesse de vários pesquisadores na prospecção de novas substâncias com propriedades antimicrobianas.

De acordo com vários autores, as substâncias tânicas, presentes nos extratos de plantas medicinais, possuem ação sobre vários microrganismos inibindo seu crescimento, o que faz dos vegetais uma excelente fonte de novos compostos biologicamente ativos (JONES et al., 1991; SCALBERT, 1991; COWAN, 1999; LOGUERCIO et al., 2005; MICHELIN et al., 2005; ANDRADE JR et al., 2006; PEREIRA et al., 2009; BEZERRA et al., 2011).

A Piptadenia stipulacea (Jurema-branca), planta da família das leguminosas, sendo rica em taninos, tem sido estudada especialmente pelo seu potencial efeito anti-inflamatório (ALBUQUERQUE; ANDRADE, 2002). Entretanto são poucos os estudos que avaliaram suas propriedades terapêuticas antimicrobianas.

Diante disso, objetivamos avaliar a atividade antimicrobiana dos taninos presentes na casca do caule da P. stipulacea (Benth) sobre cepas clínicas de S. aureus de origem bovina, obtidas por meio de swabs, a partir das narinas e úberes de bovinos.

\section{Material e Métodos}

As cascas do caule de P. stipulacea (Benth) Ducke foram coletadas e preparadas no Núcleo de Pesquisas do Semi-Árido (NUPEÁRIDO), da Universidade Federal de Campina Grande, Patos/PB. A exsicata foi depositada no Herbário Prof. Lauro Pires Xavier da Universidade Federal da Paraíba (JPB) sob código Agra et al. 3331 (JPB). 
Extrações dassubstâncias tânicas para avaliação da atividade antimicrobiana

As cascas, ao serem retiradas, foram acondicionadas em sacos plásticos para que não perdessem umidade. No laboratório foram tomadas duas amostras, as quais foram cortadas em fragmentos menores, homogeneizadas, pesadas e secas em estufa a $103 \pm 2{ }^{\circ} \mathrm{C}$ por $48 \mathrm{~h}$, para a determinação do teor de umidade (base seca). Em seguida as cascas foram secas ao ar e moídas em uma forrageira. O material foi classificado e utilizou-se o que passou por uma peneira de malha de $2 \times 2 \mathrm{~cm}$. Após esse processo foram retiradas quatro amostras, duas destas foram moídas em moinho do tipo Willey, para obtenção de um material de menor granulometria, mais homogêneo, e destinadas à quantificação das substâncias tânicas presentes em $P$. stipulacea de acordo com Paes et al. (2013). A extração dos taninos ocorreu em água, utilizando-se um digestor rotativo, com temperatura de $70 \pm 5^{\circ} \mathrm{C}$, por $2 \mathrm{~h}$. Para cada $2 \mathrm{~kg}$ de cascas foram adicionados $10 \mathrm{~L}$ de água (5:1). Cada amostra foi submetida a duas extrações (GUANGCHENG et al., 1991). A solução obtida foi homogeneizada, coada e depositada em bandejas de alumínio, em seguida alocadas em estufa com ventilação forçada e mantidas a $70 \pm 3{ }^{\circ} \mathrm{C}$ até a completa evaporação da umidade. $\mathrm{O}$ material seco, produto final do processo de evaporação corresponde ao tanino, o qual foi triturado em um multiprocessador de uso doméstico e peneirado em peneira de 60 mesh.

\section{Aquisição das cepas de Staphylococcus}

\section{aureus}

A coleta das amostras de leite e swab nasal foi realizada no Núcleo de Pesquisas do Semi-Árido (NUPEÁRIDO), município de Patos, PB, propriedade da Universidade Federal de Campina Grande (UFCG).

As amostras foram obtidas de 30 bovinos em fase de lactação, infectadas naturalmente. Após lavagem da teta com água e sabão, secagem com papel toalha e desinfecção do óstio do teto, utilizando-se álcool etílico a $70^{\circ} \mathrm{GL}$, coletou-se aproximadamente $5 \mathrm{~mL}$ de leite de cada quarto mamário reagente ao "California Mastistis Test” (CMT), de maneira asséptica, com tubo inclinado na posição horizontal. O swab nasal foi colhido e todas as amostras foram armazenadas em tubos rosqueados estéreis, identificados e enviados sob refrigeração em caixas de material isotérmico, para a realização do exame microbiológico e identificação do Staphylococcus aureus em Laboratório de Genética e Microbiologia da Universidade Federal da Paraíba - CCEN, onde foram processadas.

Neste trabalho, 11 cepas de $S$. aureus foram escolhidas: uma linhagem de $S$. aureus padrão (ATCC 25925) e dez linhagens de $S$. aureus de origem bovina obtidas de narinas $(230 \mathrm{~N}$ e $249 \mathrm{~N})$ e do úbere (114U, 235U, 250U, 257U, 310U, 319U, 324U e 357U).

A fim de identificar as cepas multirresistentes, previamente foi avaliada a sensibilidade aos antibióticos de três categorias diferentes por meio do teste de difusão de disco em placas de Petri contendo Muller Hinton Ágar (MHA) de acordo com Youn et al. (2011). As cepas foram testadas frente a $\beta$-lactâmicos (ampicilina e penicilina), bem como os aminoglicosídeos (neomicina e gentamicina) e tetraciclina. $\mathrm{O}$ antibiótico que apresentou melhor sensibilidade foi a gentamicina, sendo, portanto, este escolhido para controle negativo neste estudo.

\section{Atividade antimicrobiana}

O tanino foi dissolvido em água destilada e esterilizada e filtrado em membrana filtrante de 0,22 $\mu \mathrm{M}(\mathrm{TPP} 囚)$ na proporção de $25 \mathrm{mg}$ de tanino para cada $\mathrm{mL}$ de água destilada. Essa solução inicial foi diluída de forma seriada, obtendo-se concentrações que variaram entre $500 \mathrm{mg} / \mathrm{mL}$ e $0,976 \mathrm{mg} / \mathrm{mL}$ e que foram adicionadas individualmente às culturas bacterianas de S. aureus.

As bactérias foram previamente cultivadas em meio BHI (Brain Hearth Infusion, Sigma ${ }^{\mathrm{TM}}$ ) a $37{ }^{\circ} \mathrm{C}$ durante $24 \mathrm{~h}$, e as suspensões foram ajustadas segundo padrão de turvação correspondente a 0,5 da escala nefelométrica de McFarland. Isso corresponde a aproximadamente 1,5 x $10^{8}$ unidades formadoras de colônias (UFC) $/ \mathrm{mL}$ que foram diluídas em caldo BHI para uma concentração de $1,5 \times 10^{5} \mathrm{UFC} / \mathrm{mL}$.

Alíquotas de $50 \mu \mathrm{L}$ desses tubos foram retiradas e semeadas em placas de Petri contendo Muller Hinton 
Ágar (MHA). Em seguida foram feitos orifícios no próprio meio de cultura com tubos de vidro de $6 \mathrm{~mm}$ de diâmetro, que foram preenchidos com $25 \mu \mathrm{L}$ do tanino diluído em água destilada. A concentração inicial de tanino para diluição seriada foi de $500 \mathrm{mg} / \mathrm{mL}$. Essas placas foram mantidas na estufa a $37^{\circ} \mathrm{C}$ por $24 \mathrm{~h}$, em que foi considerada como CIM a menor concentração da droga que inibiu completamente o crescimento bacteriano (CLSI, 2010). O controle negativo consistiu em uma sequência de diluições seriadas de gentamicina na concentração de $40 \mathrm{mg} / \mathrm{mL}$. Esse antibiótico foi selecionado de acordo com o ensaio de sensibilidade descrito anteriormente.

Todo teste de sensibilidade do tanino de $P$. stipulacea foi realizado em triplicata e avaliado através da análise de variância (ANOVA) pelo teste de KruskalWallis, seguido do teste de Dun, visando comparar as tendências centrais de inibição do crescimento bacteriano (CALEGARI-JACQUES, 2003). Os testes foram considerados significantes quando o valor de $p$ foi menor que 0,05 . Os dados também foram registrados na forma de banco de dados do programa de informática SPSS (Statistical Package for Social Sciences) para Windows ${ }^{\circledR}$, versão 15.0 , e analisados por meio de estatística descritiva e inferencial.

\section{Resultados}

O protocolo utilizado possibilitou a determinação da atividade antimicrobiana de taninos presentes na casca do caule da P. stipulacea por meio da concentração inibitória mínima (CIM), em que observamos que o tanino apresenta efeito farmacológico significativo sobre as linhagens de $S$. aureus avaliadas in vitro. Foi possível observar halos de inibição com diâmetros que variaram de 12 a $36 \mathrm{~mm}$ nas diluições $500 \mathrm{mg} / \mathrm{mL}$ a $125 \mathrm{mg} / \mathrm{mL}$ (100\%); das 11 cepas, seis (54\%) apresentaram halos de inibição que variaram de 12 a 16 mm na diluição 31,25 $\mathrm{mg} / \mathrm{mL}$ (Tabela 1 ).

A inibição do crescimento ocorreu de forma homogênea, de acordo com o grau de concentração da substância tânica diluída. Os taninos na concentração de 500, 250 e $125 \mathrm{mg} / \mathrm{mL}$ não apresentaram diferenças significativas $(p=0,10)$ das médias do diâmetro dos halos de inibição do crescimento de $S$. aureus, mas foram consideradas significativas $(p<0,05)$ quando comparadas com as médias do diâmetro dos halos nas concentrações de 62,5 e $31,25 \mathrm{mg} / \mathrm{mL}$, o que pode estar relacionado a menor atividade antimicrobiana do tanino para cepa de $S$. aureus nessas últimas concentrações. Desta forma, observamos uma associação entre a

TABELA 1: Concentração Inibitória Mínima (CIM) e diâmetro dos halos de inibição (mm), em meio sólido da solução tânica $(\mathrm{mg} / \mathrm{mL})$ de Piptadenia stipulacea sobre Staphylococcus aureus de origem bovina.

\begin{tabular}{cccccc}
\hline Microrganismo & $\mathbf{5 0 0} \mathbf{~ m g} / \mathbf{m L}$ & $\mathbf{2 5 0} \mathbf{~} \mathbf{g} / \mathbf{m L}$ & $\mathbf{1 2 5} \mathbf{~} \mathbf{g} / \mathbf{m L}$ & $\mathbf{6 2 , 5} \mathbf{m g} / \mathbf{m L}$ & $\mathbf{3 1 , 2 5} \mathbf{~ m g} / \mathbf{m L}^{*}$ \\
\hline ATCC 25925 & 20 & 16 & 15 & 14 & 09 \\
$\mathbf{2 3 0 N}$ & 32 & 25 & 19 & 16 & 09 \\
$\mathbf{2 4 9 N}$ & 36 & 32 & 30 & 20 & 14 \\
$\mathbf{1 1 4 U}$ & 28 & 24 & 17 & 12 & 08 \\
$\mathbf{2 3 5 U}$ & 33 & 28 & 25 & 16 & 12 \\
$\mathbf{2 5 0 U}$ & 24 & 22 & 21 & 15 & 12 \\
$\mathbf{2 5 7 U}$ & 36 & 30 & 22 & 12 & 08 \\
$\mathbf{3 1 0 U}$ & 29 & 21 & 16 & 13 & 15 \\
$\mathbf{3 1 9 U}$ & 33 & 29 & 26 & 20 & 13 \\
$\mathbf{3 2 4 U}$ & 29 & 26 & 25 & 21 & 16 \\
$\mathbf{3 5 7 U}$ & 28 & 28 & 24 & 21 & $11,36 \pm 2,908^{\mathrm{b}}$ \\
\hline Média \pm DP & $29,82 \pm 4,895^{\mathrm{a}}$ & $25,55 \pm 4,612^{\mathrm{a}}$ & $21,82 \pm 4,708^{\mathrm{ab}}$ & $16,36 \pm 3,557^{\mathrm{b}}$ & \\
\hline
\end{tabular}

*Médias seguidas pela mesma letra não diferem entre si, pelo teste de Kruskal-Wallis $(p<0.05)$. $\mathrm{N}=\mathrm{Narina}$; U Úbere; *CIM = Concentração Inibitória Mínima. 
redução na concentração de tanino e o diâmetro dos halos.

\section{Discussão}

Bezerra et al. (2011) avaliaram a atividade antimicrobiana do extrato vegetal de várias partes da P. stipulacea sobre microrganismos gram-negativos e gram-positivos, dentre os quais $S$. aureus, e observaram atividade antimicrobiana apenas no extrato da casca. Isso indica que os teores de taninos são distribuídos de forma heterogênea em diversas partes da planta. Cepas de $S$. aureus isoladas a partir de bovinos foram resistentes ao extrato puro da casca de $P$. stipulacea (TREVISAN et al., 2009).

A divergência de resultados pode estar relacionada às diferentes metodologias para obtenção do extrato (TREVISAN et al., 2009), à espécie e à linhagem do microrganismo (MICHELIN et al., 2005; TREVISAN et al., 2009), à concentração do extrato (BEZERRA et al., 2011), à espécie de planta e as suas partes (casca, folha, raiz, etc.) utilizadas para obtenção do extrato (PEREIRA et al., 2009; BEZERRA et al., 2011) e à diluição adotada, o que provavelmente está relacionada à quantidade de taninos encontrados no extrato (TREVISAN et al., 2009).

Substâncias tânicas presentes no extrato de $P$. stipulacea formam um complexo enzimático capaz de provocar danos à parede celular e citoplasmática, inviabilizando a troca de íons essenciais para a sobrevivência microbiana (LOGUERCIO et al., 2005; ANDRADE JR et al., 2006).

Desta forma, os taninos de P. stipulacea oportunizam uma alternativa aos antibióticos tradicionais, que devido ao uso abusivo têm favorecido o surgimento de resistência e multirresistência, fato que dificulta o tratamento de infecções causadas por $S$. aureus, sendo uma fonte para a produção de compostos antimicrobianos. Novos estudos são necessários para isolar e avaliar o mecanismo de ação dos taninos presentes nos extratos de $P$. stipulacea.

Os resultados obtidos indicam que os taninos presentes na casca do caule de $P$. stipulacea, além de apresentar atividade antimicrobiana in vitro sobre $S$. aureus, podem servir como antibacteriano natural, bem como podem ser utilizados em combinação com outros fármacos para aumentar a eficiência destes, contribuindo para o tratamento contra microrganismos que apresentam resistência aos protocolos convencionais.

\section{Referências}

ALBUQUERQUE, U. P.; ANDRADE, L. C. H. Usos de recursos vegetais da caatinga: o caso do agreste do estado de Pernambuco (Nordeste do Brasil). Interciência, Caracas, n. 7, v. 27, p. 336-346, 2002.

ANDRADE JR, R. G.; GINANI, J. S.; LOPES, G. K. B.; DUTRA, F.; ALONSO, A.; HERMES-LIMA, M. Tannic acid inhibits in vitro iron-dependent free radical formation. Biochimie, Paris, v. 88, n. 9, p. 1287-1296, 2006.

BEZERRA, D. A. C.; RODRIGUES, F. F. G.; COSTA, J. G. M.; PEREIRA, A. V.; SOUSA, E. O.; RODRIGUES, O. G. Abordagem fitoquímica, composição bromatológica e atividade antibacteriana de Mimosa tenuiflora (Wild) Poiret e Piptadenia stipulacea (Benth) Ducke. Acta Scientiarum Biological Sciences, Maringá, v. 33, n. 1, p. 99-106, 2011.

CALEGARI-JACQUES, S. M. Bioestatística: princípios e aplicações. Porto Alegre: Artmed, 2003. 264 p.

CLSI - CLINICAL AND LABORATORY STANDARDS INSTITUTE. Performance standards for antimicrobial susceptibility testing, twentieth information supplement. v. 32, n. 3. Wayne: CLSI, 2010. 188 p.

COWAN, M. M. Plant products as antimicrobial agents. Clinical Microbiology Reviews, Washington, v. 12, n. 4, p. 564-582, 1999. GUANGCHENG, Z.; YUNLU, L.; YAZAKI, Y. Extractive yiels, Stiasny values and polyflavonoid content in barks from six acacia species in Australia. Australian Forestry, Queen Victoria, v. 54, n. 3, p. 154-156, 1991.

JONES, G.; MCALISTTER, A. T.; MUIR, A. D.; CHENG, K. J. Effects of sainfoin (Onobrychis viciifolia scop.) condansed tannins on growth and proteolysis by four strain of ruminal bacteria. Applied and Environmental Microbiology, Washington, v. 60, n. 4, p. 1374-1378, 1991.

KLEIN, G.; GOULART, L. S. Multiresistant Staphylococcus aureus biological materials prevalence from Osvaldo Cruz Laboratory, Uruguaiana-RS. Brazilian Journal of Pharmacognosy, Curitiba, v. 89, n. 2, p. 121-124, 2008.

KOZERSKI, N. D.; OLIVEIRA, J. L. P.; MOURA, R. A.; SILVA, D. R.; OLIVEIRA, A. F.; MELlO, P. L.; AGOSTINIS, D. D. G.; OTUTUMI, L. K.; MARTINS, L. A. Antimicrobial profile of multidrug-resistant Staphylococcus spp. isolated from bovine mastitis cases in the northwest region of Paraná State, Brazil. African Journal of Microbiology Research, Benin City, v. 8, n. 37, p. 3392-3397, 2014.

LOGUERCIO, A. P.; BATTISTIN, A.; VARGAS, A. C.; HENZEL, A.; WITT, N. M. Atividade antibacteriana de extrato hidroalcoólico de folhas de jambolão (Syzygium cumini (L.) Skells). Ciência Rural, Santa Maria, v. 35, n. 2, p. 371-376, 2005. 
MELLO, P. L.; AGOSTINIS, R. O.; BARZON, E. M.; COLOMBO, R. B.; SILVA, A. V.; MARTINS, L. A. Prevalência da mastite subclínica e associação dos agentes etiológicos com a contagem de células somáticas de vacas leiteiras da região Sudoeste do Paraná. Veterinária e Zootecnia, Botucatu, v. 19, n. 4, p. 513-521, 2012.

MICHELIN, D. C.; MORESCHI, P. E.; LIMA, A. C.; NASCIMENTO, G. G. F.; PAGANELLI, M. O.; CHAUD, M. V. Evaluation of the antimicrobial activity of vegetal extracts. Brazilian Journal of Pharmacognosy, Curitiba, v. 15, n. 4, p. 316-320, 2005.

PAES, J. B.; DINIZ, C. E. F.; LIMA, C. R.; BASTOS, P. M.; NETO, P. N. M. Taninos condensados da casca de angico-vermelho (Anadenanthera colubrina var. cebil) extraídos com soluções de hidróxido e sulfito de sódio. Revista Caatinga, Mossoró, v. 26, n. 3, p. 22-27, 2013.

PEREIRA, A. V.; TREVISAN, L. F. A.; AZEVÊDO, T. K. B.; PEREIRA, M. S. V.; PEREIRA, M. V.; RODRIGUES, O. G.; LIMA, E. Q.; PEREIRA, J. V. Determinação dos padrões de resistência de $S$. aureus aos extratos de plantas medicinais do nordeste brasileira. Agropecuária Técnica, Areia, v. 30, n. 1 p. 42-47, 2009.

PEREIRA, R. S.; SUMITA, T. C.; FURLAN, M. R.; JORGE, A. O.; UENO, M. Antibacterial activity of essential oils on microorganisms isolated from urinary tract infection. Revista de Saúde Pública, São Paulo, n. 2, v. 38, p. 326-328, 2004.

SANTOS, A. L.; SANTOS, D. O.; FREITAS, C. C.; FERREIRA, B. L. A.; AFONSO, I. F.; RODRIGUES, C. R.; CASTRO, H. C. Staphylococcus aureus: visiting a strain of clinical importance. Jornal Brasileiro de Patologia e Medicina Laboratorial, Rio de Janeiro, v. 43, n. 6, p. 413-423, 2007.
SCALBERT, A. Antimicrobial properties of tannins. Phytochemistry, Leiden, v. 30, n. 12, p. 3875-3883, 1991.

TRABUlSI, L. R.; ALTERTHUM, F. Microbiologia. 5 ed. São Paulo: Atheneu, 2009. 105 p.

TREVISAN, L. F. A.; PEREIRA, A. V.; MELO, M. A.; ALBUQUERQUE, A. C. L.; PEREIRA, M. S. V. P.; RODRIGUES, O. G.; LIMA, E. Q.; PEREIRA, J. V. Resistência microbiana aos fármacos no tratamento de mastites: alternativas naturais para romper essa barreira. Agropecuária Técnica, Areia, v. 30, n. 1, p. 51-56, 2009.

VIÇOSA, G. M.; MORAES, P. M.; YAMAZI, A. K.; NERO, L. A. Enumeration of coagulase and thermonuclease-positive Staphylococcus spp. in raw milk and fresh soft cheese: an evaluation of Baird-Parker agar, rabbit plasma fibrinogen agar and the Petrifilm ${ }^{\mathrm{TM}}$ Staph Express count system. Food Microbiology, Summit-Argo, v. 27, n. 4, p. 447-452, 2010.

YOUN, J.; YOON, J. W.; KOO, H. C.; LIM, S. K.; PARK, Y. H. Prevalence and antimicrogram of Staphylococcus intermedius group isolates from veterinary staff, companion animals, and the environment in veterinary hospitals in Korea. Journal of Veterinary Diagnostic Investigation, Thousand Oaks, v. 23, n. 2, p. 268-274, 2011. 